\title{
A Problemática do Desenvolvimento, na Optica de um Economista menor
}

Francisco José DE Souża

\section{I — PROSPECÇÃO INICIAL}

$\mathrm{T}$

ODo brasileiro, ao debruçar-se, meditativamente, sôbre as causas impeditivas do crescimento nacional, em função de sua potencialidade econômica, é atraido ao devaneio, pelo esfôrço sôbre-humano da análise, observação e pesquisa em têrmos de gigantismo mental, que o arroja, inelutàvelmente, ao torvelinho rodopiante da problemática inextricável e esmagadora.

$1 / 2$. Essa indecisão entre meios e fins, para dominar fatos e valôres, torna o incapaz de formular um pensamento ambivalente, ou seja, um raciocinio conciso e condensado, pela aplicação do processo de sintese, na conciliação das partes analisadas que compõem o todo; isto é, o enfoque pluridimensional, a um tempo. cogniscitivo e valorativo, do planejamento econômico globalista.

I/3. Assim, o observador deve evitar, a qualquer custo, a atração dispersiva da "recherche du temps perdu", proustiana, ante os erros, e desconcertos, e desmandos cometidos ao longo da vida nacional e, quiçá, na própria fase colonial, como nos revela a história econômica do Brasil.

I/4. Obnubilinados, mas eufóricos, pela ação estimulante ou psicodélica do "porque-me-ufanismo", fomos praticando desatinos sôbre desatinos, a pretexto de explorar, racionalmente, isto é, sol critérios de política econômica ideal, a rentabilidade ou produtividade de algumas riquezas locacionais ou setoriais, se bem que, de uma forma ou de outra, lográssemos alargar o mercado interno, baixo de poder aquisitivo, que mantém marginalizados, na partilha do produto nacional ou renda "per capita", talvez mais de $50 \%$ de brasileiros.

I/5. O subdesenvolvimento ou dependência econômica $e$ politica, que marca e identifica as nações pobres ou periféricas, 
é uma questão dilemática e de etiologia patológica: provém da degenerescência das elites dirigentes ou da alienação ideológica; de ativismo de sub-raças de "mestiços neurastênicos", no dizer euclideano; ou de caquexia alvar congênita, e, enfim, de corrupção visceral ou burrice conata. Em qualquer dos casos, o resultado aí está - a incapacidade no sanear, no organizar e no tornar florescente a economia nacional (em permanente regime de crises), através do planejamento sensatamente exequíivel.

I/6. Guerreiro Ramos, $\left(^{1}\right)$ a êsse propósito, lembra que Paulo Prado, em seu "Retrato do Brasil", - "aponta no brasileiro caracteristicas que pressupõem uma temporalidade típica de atraso." Enquanto em Israel, por exemplo, e a propósito do "milagre", escreve um articulista brasileiro: $\left({ }^{2}\right)$

"Por que houve o milagre de Israel? Porque seu povo, seu govêrno, sua gente do mundo inteiro, compreendeu que a ciência e a técnica, carregadas com sabedoria nas mãos dos que aprenderam a querer, são capazes de fazer correr água nos desertos e nascerem flôres nas montanhas de pedra."

I/7. No caso brasileiro, tal defasagem "a rebours", conformista com a condição semi ou para-colonialista, de meros tornecedores de matérias-primas ou de produtos agrícolas dispensáveis, como o café, por exemplo, ou, ainda, de produtos da atividade extrativa (minérios, madeiras etc.), a preços vis $\left({ }^{\star}\right)$ e variáveis ao alvedrio do monopolista de compra ou monopsônio, a par da educação deficiente em relação ao "know-how", $\left(^{3}\right)$ e deformada pela concepção idealista de um bem-estar absoluto ou baseado na condenada propriedade privada do uso, gôzo e abuso de bens de consumo suntuários, o modo dos eletrodomésticos e quejandos.

I/8. Como observou um sagaz ensaista, $\left({ }^{4}\right)$ a propaganda de determinada "way-of-life", alienígena, com a chancela oficial

(1) Guerreiro Ramos - Administração e Estratégia do Desehvolvimento, pág. 32. Fund. Getúlio Vargas, Rio, 1966.

(2) Fausto Gayoso - O Brasil e o Milagre de Israel, "in" Correio da Manhã, de 12-11-1967, pág. 2, 2 Caderno.

(3) Fausto Gayoso - Previsáo indica queda na Economia dos EUA. "Correio da Manhã, idem, idem.

(4) Claudio de Araújo Lima - Imperialismo e Angústia, pág. 9. Edit. Civilização Brasileira, Rio, 1960.

(*) Significativamente, o "Correio da Manhã", de 12-11-1967, publicou o seguinte:

"Para os países subdesenvolvidos a previsăo é de que continuarão caindo os preços de seus principais produtos de exportação, com exceção dos minerais, beneficiados pelo consumo extra da indústria bélica dos Estados Unidos." (Pág. 2, do $2^{\circ}$ Caderno). 
de opção irreversivel e condicionada por fatôres "de organização da desorganização", cria a mentalidade orientada para o "dolce far-niente", ou seja, a classe ociosa criticada por Veblen. $\left(^{5}\right)$

I/9. O crescimento econômico dos países atrasados, não pode, é evidente, ser estruturado num paradigma de plano de ação para uso geral e rígido. Seria a panacéia do planejamento.

I/10. Aos responsáveis - racionalizadores e executores cumpre estar atentos às peculiaridades da estrutura econômica: meio; climas; população; potencial hidráulico e do subsolo; fertilidade da terra e outros fatôres que influenciam, condicionam ou determinam a exploração em moldes de economicidade: investimentos "versus" rentabilidade.

I/11. Sobretudo, deve-se considerar que a ajuda das nações ricas, não é, nem poderá ser, sincera ou desinteressada, mas subordinada aos interêsses de suas próprias economia e finanças.

I/12. Daí a exata observação de Georges Balandier $\left({ }^{6}\right)$ de que as sociedades tècnicamente mais adiantadas entram necessàriamente em contacto com as sociedades menos desenvolvidas em posição desigual, e tendem a reduzir estas últimas aos limites de seus espaços econômico e politico, para concluir que - "A exatidão dessas afirmações se aplica tanto ao colonialismo do passado quanto ao colonialismo disfarçado dos povos atualmente dominantes."

I/13. Outro depoimento significativo, aliás de norte-americano e professor universitário (7) nos adverte que:

"O clima é ainda pior quando se trata da discussãó do desenvolvimento econômico dos países subdesenvolvidos. Um labirinto de enganos, de hipocrisia e de fingimento confunde a discussão, tornando necessário que se faça enorme esfôrço a fim de se atravessar a cortina de fumaça, que obscurece o tema principal. O que é fundamental é que o desenvolvimento econômico das nações subdesenvolvidas é profundamente contrário aos interêsses dominantes dos países capitalistas."

I/14. Evidentemente, o assunto já era de inteiro conhecimento do grande Alberto Tôrres $\left({ }^{8}\right)$, quando, há mais de meio século, advertia, debalde, que:

(5) Thorstein Veblen - Teoría de la Clase Ociosa. Prefácio, pág. 7, Fondo de Cultura Económica, México.

(6) Apud L. J. LEBRET - "in" Suicídio ou Sobrevivência do Ocidente? Pág. 174. Livr. Duas Cidades, S. Paulo, 1960.

(7) Paul A. Branan - A Economia Politica do Desenvolvimento Eco. nômico, pág. 22. Zahar Editôres, Rio, 1960.

(९) Alberto Tôrres - A Organização Nacional, pág. 208. Imprensa Nacional, Rio, 1914. 
“A exploração econômica de um território convém mais, freqüentes vêzes, às nações fortes, do que a ocupação política. A exploração não é impedida pela paz, e pode, pelo contrário, achar, em seu regímen, melhores bases de apoio e desenvolvimento."

I/15. Mais que antigamente, na atualidade a politica internacional ou diplomacia está condicionada por ideologias. Melhor diríamos: a fase atual da evolução histórica da humanidade, caracteriza-se pelo conflito de misticas. A implicação sujeitoobjeto (pensamento-realidade) ou seja, o transunto da idéia para o mundo vivo da realidade, a passagem do abstrato para o concreto, efetua-se, como doutrina Mannheim, mediante a relação dialética hegeliana de topia-utopia-topia, e por isso, sublinha o sociólogo, - a ideologia, em sua concepção particular, "opera primàriamente como psicologia de interêsses." ( $\left.{ }^{9}\right)$

\section{II - ABORDAGEM OPCIONAL}

II/1. Mas, o que vem a ser desenvolvimento? Meier e Baldwin $\left({ }^{10}\right)$ após insinuarem que o crescimento econômico dos paises pobres interessa aos ricos, porque amplia ou faz surgir novos mercados consumidores dos produtos de suas indústrias, apresentam a seguinte definição:

"el desarrollo económico es un proceso mediante el cual la renta nacional real de una economía aumenta durante un largo periodo de tiempo. Y si el ritmo de desarrollo es superior al ritmo de crescimiento de la problación, la renta real per capita aumentará."

II/2. De maneira que, se o desenvolvimento opera mudanças, pelo incremento do produto nacional bruto, ou líquido, conforme a mensuração aplicada, também estão implícitas modificações básicas na oferta de fatôres fundamentais, e na estrutura da demanda dos produtos, as quais, segundo os referidos tratadistas, podem ser relacionadas do seguinte modo: (11)

“a) Los cambios particulares en la oferta de los factos compreenden:

1) el descubrimiento de recursos adicionales;

2) la acumulación de capital;

3) el crescimiento de la problación;

(9) Karl Mannhrim - Ideologia e Utopia, pág. 33. Edit. Globo, Pôrto Alegre, 1950.

(10) Gerald M. Meier e Robert E. Baldwin - Desarrollo Econòmico. pág. 4. Aguilar Ediciones. Espanha, 1964.

(11) Gerald Mi. Meifr e Robert E. Baldwin - Ibidem, pág. 4. 
4) la introducción de nuevas y mejores técnicas de producción;

5) la mejora de cualificación personal;

6) otras modificaciones institucionales y de organización.

b) Los cambios particulares en la estructura de la demanda están ligados a la evolución de:

1) el tamaño y la composición por edades de la problación;

2) el nivel y la distribución de la renta;

3) los gustos;

4) otras condiciones institucionales y de organización."

II/3. Surge, agora e decisivamente, o problema da cooptação: progresso agropastorial ou industrial? Realmente, à agricultura é fase anterior à indústria $e$ as nações altamente industrializadas tiveram na agricultura a base financiadora de seu avanço tecnológico.

II/4. Relevando essa lição de história econômica, Bryce $\left({ }^{12}\right)$ opina:

"... para os países subdesenvolvidos cujas receitas provêm, em grande parte, da venda dos produtos agrícollas, da mineração, da pesca e de atividades florestais, maiores seriam os lucros - e mais rápidos - se cuidassem, em primeiro lugar, de incrementar o desenvolvimento dessas atividades, ao invés de se lançarem apressadamente em esquemas de industrialização em grande escala. Freqüentemente muito mais se pode acrescentar à renda nacional, com o mesmo capital, se êste fôr aplicado na compra de equipamento agrícola ou de sementes selecionadas e não em complexos empreendimentos industriais. O desenvolvimento da agricultura não será tão extraordinário quanto o espetáculo do crescimento industrial, mas pode representar a alternativa mais justa, à qual se deve atribuir inteira prioridade."

II/5. A nosso ver, exata seria a alternativa se focalizada nos estritos limites de aceleramento econômico. Mas, na realidade, o fato político, a que se subordina o econômico, se bem seja o fundamental ou determinante, evidencia a discriminação entre nações dominantes e dominadas e, verdadeiramente, a ex-

(12) Murray D. Bryce - Desenvolvimento Industrial, pág. 19. Livraria Pioneira Editôra. S. Paulo, 1964. 
periência mostra que não pode haver hegemonia politica ou grande potência, sem o avanço, "pari passu", do binômio: indústria e tecnologia.

II/6. Eis que, em apoio da tese, trazemos o depoimento categorizado de Myrdal: $\left({ }^{13}\right)$

"Em certo sentido a indústria representa um estágio mais elevado da produção. O desenvolvimento industrial nos paises avançados se tem processado paralelamente ao seu espetacular progresso econômico e à elevação de seu padrão de vida; muitos de seus produtos transfor. maram-se, na verdade, em símbolos de alto nível de vida, Também, nos paises subdesenvolvidos, a produtividade da fôrça de trabalho tende a ser consideràvelmente maior na indústria do que nas tradicionais atividades agrícolas. A industrialização e o aumento da parte da população ativa empregada na indústria são, portanto, um fator de aumento da renda nacional per capita. Nos países como a India e o Japão, de alta densidade demográfica em relação aos seus recursos naturais e, em particular, em relação à terra, a indústria representa, virtualmente, a única esperança de aumento da produtividade do trabalho e de elevação dos padrões de vida, embora muito seja feito para melhorar a agricultura. Mas, até mesmo nos países de escassa população - como por exemplo em muitos países da América Latina - a exploração bem sucedida de uma proporção mais favorável entre a população e os recursos naturais exige, principalmente, o desenvolvimento da indústria."

\section{III - DESENVOLVIMENTO E TECNOLOGIA}

III/1. Revolução industrial e aceleramento industrial são idéias motivadoras que, em têrmos de avanço da técnica de planejamento e de execução, retratam a era tecnocrática oul a "management age" de que falam Burnham e Siegfried. ( $\left.{ }^{14}\right)$

III/2. O poder decisório ou função administrativa tem por base a organização científica do trabalho, segundo os estudos pioneiristas de Taylor e Fayol. Segundo a doutrina fayolista, a atividade executória ou fato administrativo conjuga as operações

(13) GunNar MYrdal - Teoria Econômica e Regiões Subdesenvolvidas. M.E.C., Rio, 1960.

(14) Burnham e Siegreried (André) - Cfr. Jacques Billy, "in" Os Técnicos e o Poder, "passim." Difusão Européia do Livro, S. Paulo, 1961. 
ou funções de previsão ou planejamento, organização, comando, coordenação e contrôle. $\left({ }^{15}\right)$

III/3. Para uns, o planejamento ou previsão é antitético ao "laisser faire, laisser passer", enquanto a maioria, conciliatória, mormente nos países atrasados, sem falar na economia socialista, admite o planejamento governamental subordinativo da expansão das micro-economias.

III/4. Não poucos autores têm salientado essa pluralidade conceptual da palavra planejamento. Se a tecnologia socialista considera a planificação como uma visão ampla e total da integração vertical da macro-economia, outros o dividem e subdividem em mini-planos e projetos, regionais, locacionais ot setoriais.

III/5. Haja vista a explanação que, a êssé respeito, oferece Herbert Simon: (16)

"Emprega-se hoje a palavra planejar com mais freqüência como rótulo de lema politico ou de inconfor* mismo politico, do que como designação de determinada classe de atividade administrativa. Para os seus entusiastas, planejar é sinônimo de coordenar, prever, antecipar -se ao futuro; poder-se-ia dizer que, para êles, planejamento é sinônimo de racionalidade. Aos olhos de seus adversários, planejar envolve a idéia de arregimentação, e até de coletivismo. A maioria das emoções tempestuosas provocadas pelos têrmos planejar e planejamento relaciona-se exclusivamente com determinada classe de planejamento: a dos sistemas econômicos dirigidos pelo Estado."

III/6. De forma que o planejamento é um processo metodológico; uma sistematização coordenada e cognitiva da visão sócio-econômica; um método ou caminho a seguir com a utilização de meios pròpriamente selecionados, para alcançar determinado fim, no caso, o desenvolvimento uniforme da infraestrutura econômica.

III/7. Ionides (17) debatendo o tema - "Objetivos e implicações do desenvolvimento econômico - informa que, segundo Eugene Black,

(15) Henry Fayol - Administração Industrial e Geral, pág. 13. Editôra Atlas S. A., 6" Edição, S. Paulo, 1965.

(16) Herbert Simon - "Apud" Henri N. Bunbury "in" Uma Teoria Geral do Planejamento, de Benedicto Silva, pág. 132. Ed. Fund. Getúlio Vargas, Rio, 1964.

(17) Eugene Black - "Apud" M. G. Ionides "in" Organização Administrativa para o Desenvolvimento Econômico, pág. 1, Ed. Fundação Getúlio Vargas, Rio, 1964. 
"Ninguém ainda codificou regras para uma contribuição efetiva ao desenvolvimento econômico, e eu declaro desconhecer se existem cinco, cinqüenta ou quinhentos princípios, que possam ser úteis aos que se dedicam à assistência econômica.

A assistência será efetivamente válida se na realidade vier a constituir um esfôrço sério e bem estudado para melhorar a economia do país beneficiado."

III/8. Se, pois, o avanço econômico racional depende da planificação global ou estatal, com ênfase dos setores prioritários e em perfeito sincronismo com a política financeira, cumpre dotar as organizações ligadas ao desenvolvimento econômico com os recursos humanos capazes, no sentido da eficiência ou produtividade. E o que, a propósito, nos ensina Harbison $\left({ }^{18}\right)$, em seu estudo sôbre o capital humano de alto nível, como medida de progresso econômico:

"Em linhas gerais, o estágio de desenvolvimento de um pais, quando avaliado por êsses indicadores do potencial humano, demonstra uma correlação positiva com a fase de desenvolvimento acusada pelas estimativas da renda nacional per capita. As diferenças relativas, todavia, entre alguns países avançados e outros menos desenvolvidos podem ser maiores, em têrmos do potencial humano de alto nível, do que em têrmos da renda nacional per capita. O quadro seguinte, apresentado apenas para fins ilustrativos, demonstra êste fato muito claramente:

\begin{tabular}{|c|c|c|}
\hline PA I S & $\begin{array}{l}\text { NO DE PESSOAS EM } \\
1.000 \text { HABITANTES } \\
\text { COM O MINIMO DE } \\
12 \text { ANOS DE } \\
\text { INSTRUST̃O }\end{array}$ & $\begin{array}{l}\text { RENDA NACIONAL } \\
\text { "PER CAPITA" } \\
\text { EM DÓLARES } \\
\text { AMERICANOS }\end{array}$ \\
\hline 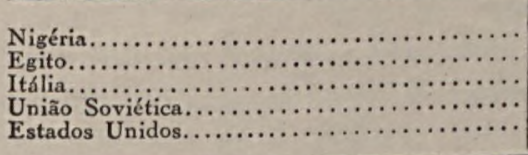 & $\begin{array}{r}0,8 \\
10,7 \\
31,4 \\
112,6 \\
288,0\end{array}$ & $\begin{array}{r}64 \\
110 \\
594 \\
721 \\
2.800\end{array}$ \\
\hline
\end{tabular}

"A Itália, por exemplo, tem 39 vêzes mais pessoas com 12 ou mais anos, do que a Nigéria; a renda nacional per capita, entretanto, é sòmente cêrca de nove vêzes maior. De igual forma, a U.R.S.S. possui um potencial

(18) Frederick H. Harbison - "in" Recursos Humanos para o Desenvolvimento, págs. 3/4. Edit. Fund. Getúlio Vargas, Rio, 1965. 
humano de alto nivel per capita 11 vêzes maior do que - Egito, mas sua renda nacional per capita é apenas sete vêzes maior.

Por outro lado, as diferenças relativas das reservas de potencial humano de alto nivel e da renda nacional entre os Estados Unidos e o Egito são, aproximadamente, iguais, ao passo que a comparação entre os Estados Unidos e a União Soviética demonstra uma diferença relativa maior na renda per capita do que na reserva do potencial humano de alto nivel."

\section{IV — CONCLUSÃO}

IV/1. Como vimos, e para concluir, é o elemento humano que resolve o problema do aceleramento da expansão econômica. Dos dias correntes é o soberbo exemplo oferecido pelo Japão e pela Alemanha Ocidental, seguidos pela Inglaterra, França e Itália. De uma economia aniquilada do após-guerra, partiram, "ab ovo", para a reconstrução naçional, expandindo a industrialização e a tecnologia, em nível acima ao do periodo anterior à conflagração mundial de 1939/1945.

$\mathrm{IV} / 2$. Em nosso caso, que é o de um país jogado ao vórtice inflacionário e à anarquia financeira, onde os salários, para usarmos a expressão de Malthus, crescem em proporção aritmética, em contraste com a progressividade geométrica dos preços, pela inflação dos custos, e que se poderia representar pelo fenômeno da "bola de-neve", invocariamos, sem rebuscamentos semânticos, tão ao gôsto atual, a expressividade do progresso sino-germano-israelita, e, oxalá, sôbre êle meditassem as nossas autoridades administrativas. 